\title{
Decision-Making on Incoterms 2020 of Automotive Parts Manufacturers in Thailand
}

\author{
Juthathip SURARAKSA ${ }^{1}$, Chompoonut AMCHANG ${ }^{2}$, Nutcharin SAWATWONG ${ }^{3}$
}

Received: July 18, 2020 Revised: August 23, 2020 Accepted: August 28, 2020

\begin{abstract}
The objective of this research is to examine the factors affecting the decision-making of International Commercial Terms (Incoterms) of automotive parts manufacturers in Thailand. This mixed method study applied qualitative and quantitative research methods and utilized the analytical hierarchy process (AHP) to prioritize the significance of the factors. By an in-depth literature review and expert interview, four main criteria were identified. These criteria include Operating costs, Cooperation and bargaining power, Knowledge and understanding and Operation duration then main criteria divided into fifteen sub-criteria. The common Incoterms, Ex Works (EXW), Free On Board (FOB), Free Carrier (FCA), and Cost, Insurance and Freight (CIF), were determined as alternatives to the incoterms through a preliminary survey. The results revealed that the operating costs were the most important factor for the company. Moreover, it was discovered that this was consistent with the priority of the secondary factors, which included the annual budget for the transportation expenses and product value at one time. The respondents' perspective suggested that FCA was the most appropriate Incoterms for international trade for a company. The findings of this research suggest a hierarchy model for organizations to prioritize the significant factors in order to make a decision on the most appropriate Incoterms.
\end{abstract}

Keywords: Incoterms, Decision Making, Analytical Hierarchy Process, Automotive, International Trade

JEL Classification Code: B27, F13, P33, G41

\section{Introduction}

Import and export are the key components of all industries, particularly those related to production where the importing of products or raw materials are required for the production process to export the final products abroad. The trade cost and the production cost are significant factors that affect competitiveness in international trade particularly in developing countries (Arvis, Duval, Shepherd, Utoktham,

${ }^{1}$ First Author. Lecturer, Faculty of Logistics, Burapha University, Thailand. Email: juthathip@go.buu.ac.th

${ }^{2}$ Corresponding Author. Lecturer, Faculty of Logistics, Burapha University, Thailand [Postal Address: 169 Long-hard Bangsean Road, Saensuk, Mueang, Chonburi 20131, Thailand]

Email: chompoonut@go.buu.ac.th

${ }^{3}$ International Trade and Logistics Management Program, Faculty of Logistics, Burapha University, Thailand.

Email: nutcharin118@gmail.com

(c) Copyright: The Author(s)

This is an Open Access article distributed under the terms of the Creative Commons Attribution Non-Commercial License (https://creativecommons.org/licenses/by-nc/4.0/) which permits unrestricted non-commercial use, distribution, and reproduction in any medium, provided the original work is properly cited.
\& Raj, 2016; De, 2007; Tu \& Giang, 2018). With the huge number of suppliers and customers, the negotiation of trade agreements is complicated and diverse; such as, delivery, transport expenses, risk of transport, and obligations (Chamsuk, 2018). Therefore, a trade agreement between the importer and exporter or International Commercial Terms (Incoterms) is crucial since it determines the roles, obligations, transport liability, and compensation that is accepted globally (Sawangpaew, 2012).

Incoterms are the regulations or terms of product delivery that are a set international standard for making a sales contract between the buyer and seller, which have been published by the International Chamber of Commerce (ICC) and are consistent with the trade principles of the United Nations (UN). That being said, the buyer and seller need to acknowledge the scope of the obligation of the expenses and risks to create understanding between both parties who may have a different culture (Imarromna, 2011; Khreusaeng, 2007).

According to the supply chain of automotive part cooperation companies, a semi-assembly refers to a company that supplies a finished product that is functionally 
independent in the assembly of an automobile as a firsttier supplier, and a secondary parts cooperation company is a second-tier supplier that supplies a product to a first-tier supplier. Finally, a third-party cooperation company refers to a company that supplies components to the second (An \& Kim, 2019). For this reason, automotive parts manufacturers are the supporters of the production of automobile manufacturers and automotive assembly entrepreneurs to timely deliver to domestic and international customers. Thus, automotive parts manufacturers in Thailand are a key factor in automobile production since they deliver up to $80 \%$ of the automotive parts for vehicle production in the country (Thailand Board of Investment, 2017). As a result, the automobile manufacturing and assembly companies could save the cost of transport and waiting time when compared to manufacturers in other countries.

The automotive industry is one of the significant industries for Thailand's economic growth. Currently, Thailand is one of the major bases of automobile production in Asia and the largest production base in ASEAN. A number of first, second and third tier companies are located in Thailand. Therefore, one of those has been selected as a case study of this research, which is a manufacturer of automotive seat assembly and accessories as a first-tier supplier that regularly conducts international commercial transactions. The company imports the raw materials from overseas for production and exports the final products abroad, as well as distributes in the domestic market. An international trade agreement is a method that the company uses for conducting negotiations and making agreements with its suppliers and customers. Recently, there have been some problems; such as, inappropriate terms and conditions for a certain period, which have affected the cost of the imports, delay of the exports, and the decreasing satisfaction of customers.

Thus, this research aimed to study the factors affecting the decision-making of utilizing the Incoterms in the automotive parts production and assembly industry and assess the alternatives to the international trade agreement as guidelines for the appropriate decision-making. The main contribution consisted of three aspects. First, the analytical hierarchy process (AHP) was used to analyze and rearrange the factors to prioritize the significant factors based on the respondents' perspective. Second, the use of the AHP to choose the Incoterms allowed the managers of the automotive industry to confidently make a firm decision. Lastly, the findings of this study could be used as guidelines for making decisions or the criteria for making decisions of the appropriate Incoterms.

The remainder of this research is organized as follows: section 2 presents literature review. Then, the research background is explained in section 3 and the methodology is described in section 4. After that, the results of decision making are defined and discussed in section 5. Finally, conclusions, limitations, and directions of future research are discussed in section 6 .

\section{Literature Review}

\subsection{International Commercial Terms (Incoterms)}

The International Chamber of Commerce (ICC) developed Incoterms for the global trading system. The ICC codified the first study of most generally used trade terms as a pre-incoterms edition in 1923. Based on the findings, the ICC published the first edition with six terms and rules in 1936. The terms included: 1) FAS-Free Alongside Ship; 2) FAS- FOB-Free On Board; 3) C\&F-Cost and Freight; 4) CIF-Cost Insurance and Freight; 5) Ex Ship, and; 6) Ex Quay (International Chamber of Commerce, 2010). However, it is well-known that international trade had been happening over several millennia. Incoterms came into being to address the problem of interpretation amongst trading partners (Bergami, 2012). In addition, Incoterms were designed to harmonize the world's maritime traders and their shipping policies to reduce the number of arguments between trading partners. Incoterms were also clearly defined responsibilities between buyers and sellers, such as costs, risks, documentation, contracting for transport etc. (Stapleton, Pande, \& Brien, 2013).

Incoterms are defined as identifying a sales contract between countries who are able to determine the obligation to transport, insure, and deliver a finished product to be traded between the buyer and seller, as well as the risk of the product, which is the obligation of the seller that might convert the buyer's obligation in order to facilitate the issue of the contract. Selection of Incoterms is difficult for actors who lack knowledge (Hien, Laporte, \& Roy, 2014). To choose terms, it depends on the opportunity of stockholders in the supply chain to improve the efficiency of service on their perspective (Yaakub, Szu, Arbak, \& Halim, 2018).

ICC reviews and updates the Incoterms rules every ten years, the previous edition was published in 2010 (Lowe, 2020). ICC has announced the latest edition Incoterms 2020 Rules, which have been effective since 1 January 2020. The Incoterms 2020 Rules is the ninth edition of Incoterms, which have the aim of being more inclusive and applied with simple language for the current international trade. Generally, the main differences between Incoterms 2010 and Incoterms 2020 include: 1) DAT Incoterm changed to DPU 2) Insurance points are clarified in CIF and CIP incoterms rules 3) Costs and cost structures are now clarified 4) Security in relation to transport is now clearly detailed 5) Provisions to allow for own transport rather than assuming 3rd party transport 6) FCA, FOB and Bills of Lading 7) Presentation and design is much more user friendly (Ronai, 2020). 
Consequently, the trade terms and conditions must correspond with the changing business patterns. Incoterms 2020 are divided into four groups $(\mathrm{C}, \mathrm{D}, \mathrm{E}, \mathrm{F})$, which consist of 11 conditions clarifying the responsibilities of the buyer and seller, the fees and risk, as well as issues related to import and export (Shiphub, 2020). From 11 conditions, it can be classified into multi-modal and single-modal as follows (McKenzie, 2019):

Multi-modal: Conditions for international trade that apply to multiple modes of transport (including land, air and waterway transportation):

- EXW (Ex Works)

- FCA (Free Carrier)

- CPT (Carriage Paid To)

- CIP (Carriage and Insurance Paid to)

- DAP (Delivered At Place)

- DPU (Delivered Place Unloaded)

- DDP (Delivered Duty Paid)

Single-modal: Conditions for international trade that apply to sea and inland waterway transportation only

- FAS (Free Alongside Ship)

- FOB (Free On Board)

- CFR (Cost and Freight)

- CIF (Cost, Insurance and Freight)

Yaakub et al. (2018) examined the factors affecting the selection of the Incoterms in the production industry in Malaysia toward export efficiency. A questionnaire was used to collect the data, and the findings showed that appropriate Incoterms affected the export efficiency.

Similarly, Shangina (2007) studied the factors influencing the decision-making of an international trade agreement for the export of seafood from Norway to Japan and Russia since the export protocol was related to and controlled by different laws. Incoterms were the most important factor for the international seafood trade. In general, the quantity or value and the delivery control, which were the legal obstacle, were the factors affecting the selection of the Incoterms the most. Each country had different criteria for selecting the trade terms depending on the location, convenience of the suppliers, laws and regulations, etc.

Furthermore, Szu (2014) investigated the relationship of the factors for choosing the Incoterms to enhance the export efficiency. This quantitative research was conducted in Malaysia, and the sample group was from the Federation of Malaysian Manufacturers (FMM). Cronbach's alpha and descriptive analysis were used to analyze the reliability. The results indicated that Free on Board (FOB) was the Incoterms that were generally used in Malaysia and the relationship of the Incoterms selection affected the export efficiency.
Sabariah and Szu (2017) aimed to identify the factors affecting the choice of incoterms and figure out the most regularly used incoterms among Malaysian manufacturers. The factors can be divided into two types: The first is the internal environment, the strongest influence comes from mode of transportation, habits and practices of the organization and experience of the company. The second is the external environment, the strongest influences are freight issue, transport issue and tariff classification. The results showed that FOB (Free On Board) were the most frequently used Incoterms.

Hien et al. (2014) identified the main factors for considering and decision-making purpose which Incoterms use and to analyze the impact of the choices of Incoterms on export performance. The results highlighted that both the internal and external business environments are essential in the selection process and its contribution to improved export performance. Moreover, Incoterms utilization training also increases export performance in order to increase the awareness of the strategic dimension of Incoterms.

In another relevant study, Malfliet (2011) examined that maritime terms of Incoterms 2010 are not appropriate. The seller does not 'deliver' the container on board the vessel, but most often hands over the goods to the carrier at an inland point or terminal. Therefore, this research aimed to identify the underlying rationale. Also proposing criteria that might be applied to choose the proper Incoterm intends for supporting traders as the following aspects:

- The nature of the goods: containerized, manufactured goods, bulk goods or commodities, etc.;

- The means of transport: maritime, non-maritime or multimodal;

- The conditions of payment and the documentary requirements imposed by these conditions;

- The capabilities of and the efficiency with which the seller or the buyer can perform the obligation to deliver the contracted goods: someone will have to do it, but who does it most cheaply?

In addition, it will take into consideration how these factors influence and set the choice of Incoterm

Bergami (2006) investigated the relationship between international delivery terms and documentary requirements of the letter of credit. Based on survey results suggested that exporters, who were contracting on international delivery terms, may be exposed to non-payment risks. However, it is possible to reduce payment risk by the strategic use of international delivery terms.

Finally, Schaefer (2017) studied the negotiation and communication for making decisions on the logistics between sellers and buyers. The researcher found that the important issue of an efficient supply chain was 
the Incoterms that were normally applied by the seller and buyer to agree on the responsibilities. However, inappropriate Incoterms might lead to a communication error on the responsibilities and reveal the cost and risk to another party. Hence, the research monitored the situation that had a communication error caused by the domestic logistics to find the solution.

\subsection{The Analytical Hierarchy Process (AHP)}

The selection of the right way for a business is important for companies. Factor selection becomes a major role for managers to consider the direction to improve efficiency of their business. AHP is a method that can be applied to help the decision maker evaluate a project. AHP is applied by many authors, for example, Konpong (2019) examined the factors affecting the risk of production planning of the automotive parts industry by collecting data from an indepth interview with the relevant persons. The AHP was applied to analyze the factor loading causing the risk of the production planning.

In addition, Ngmsanengent (2012) stated that the AHP could be applied to the import and export process, which was one of the logistics activities facilitating the supply chain operation of the automotive parts industry to respond to the customer demand. Dweiri, Kumar, Khan, and Jain (2016) presented a decision model for supplier selection based on AHP in a case of automotive industry. Using AHP provided decision makers confidence in consistency. It also helps managers make decision making on a complex problem with a simple method.

Similarly, Amrina and Yusof (2013) developed an AHP based model for sustainable manufacturing performance evaluation in the automotive industry. The results revealed that the automotive industry is still focusing more on the economic factor as well as the existing performance level. Thus, it provided directions for companies to take proper actions in increasing the competitiveness and improving their higher performance. Petruni et al. (2017) proposed a method to support the evaluation and alternative for choosing the suitable Human reliability analysis technique for the automotive industry using AHP. It provides a way of assisting safety managers and risk assessors in the HRA technique selection process.

In another study, Galankashi, Helmi, and Hashemzahi (2016) applied an integrated Balanced Scorecard-Fuzzy Analytic Hierarchical Process (BSC-FAHP) model to select suppliers in the automotive industry. According to them, there are several factors to measure performance, it may make the decision makers confused. Therefore, a fuzzy AHP proposed a novel idea for the supplier selection in automotive industries. Rathi, Khanduja, and Sharma (2015) proposed the combination of fuzzy multiple attribute decision making
(MADM) with AHP in Six Sigma analysis phase. AHP is used to calculate weights of all parameters for selection of the capacity waste alternatives. The results showed the key factor for capacity waste among all alternatives.

Finally, Goepel (2017) implemented a web based AHP online system for educational and research purposes. The software supports flexible decision hierarchies, alternative and sensitivity analysis. It calculated group consensus based on Shannon $\alpha$ and $\beta$-entropy, and estimated weight uncertainties based on randomized small variations of input judgments.

From previous studies presented above, some researchers studied the Incoterms in different contexts, particularly those businesses that dealt with international transactions. The selection of the Incoterms had a direct impact on the business performance, especially the automotive industry that had a high volume of imports and exports. Thus, the study on the factors for making decisions on the Incoterms was important to the company in order to choose the most appropriate Incoterms. Hence, multi-criteria decisionmaking with the AHP resolved the problem in the hierarchy to make the appropriate decision, as it enhanced the import and export efficiency and diversification.

\section{Research Background}

Analytical Hierarchy Process (AHP) is a method to resolve complex decision-making problems with a variety of selection criteria and a wide range of decision-makers. Essentially, AHP utilizes information or expert opinions to determine the relative importance or contribution of attributes and to synthesize an optimal selection solution (Trang \& Do, 2020).

The AHP is the analytical process that is acceptable and widely used for considering the business factors in the service sector. AHP is a theory of measurement through pairwise comparisons and relies on the judgements of experts to derive priority scales (Saaty, 2008). It weighs the abstract concepts and emotions by presenting with numbers to display it concretely (Limtrakul \& Pimchanthong, 2019). The hierarchical structure of the decision with the AHP is a popular and widely used tool. The structure imitates human thinking, so the hierarchical chart is created to imitate the human decision-making process. It is classified into levels depending on the complication of the problem. Each level comprises the criteria as Level 1 is the top level, which is the problem or goal, or the focus that has only one problem or goal. Level 2 is the main criteria, which might consist of many criteria depending on how many levels are included in the chart. Level 3 is the sub-criteria, which the number of criteria relies on the information, experience or knowledge of the researcher. Level 4 is the alternatives or solutions that are appropriate to the problem in Level 1. 
In addition, pairwise comparison was applied to consider the decision and choose the alternative, which was the comparison to determine the weight of the criteria in pairs that was presented by a number to calculate the score for each alternative. The mathematical model could be written as follows:

where $2, . ., \mathrm{n}$.

$\mathrm{C}_{\mathrm{i}}=$ The criteria for the decision-making, where $\mathrm{i}=1$,

$A_{j}=$ The sub-criteria in the level that would be analyzed, where $\mathrm{j}=1,2, \ldots, \mathrm{n}$.

$\mathrm{A}_{\mathrm{ij}}=$ The paired comparison result, where $\mathrm{i}=1,2, . ., \mathrm{n}$ and $\mathrm{j}=1,2, \ldots, \mathrm{n}$.

The analysis processed each pair a time $\mathrm{C}_{\mathrm{i}}$ and $\mathrm{A}_{\mathrm{j}}$

The analysis of the matrix table $\mathrm{n} \times \mathrm{n}$ resulted in:

$A=\left[a_{i j}\right]$ where $i=1,2, \ldots, n$ and $j=1,2, \ldots, n$.

There were two rules to represent $a_{i j}$ from the paired comparison to the matrix table:

(1) If $\mathrm{a}_{\mathrm{ij}}=\alpha, \mathrm{a}_{\mathrm{ij}}=1 / \alpha$ where $\alpha \neq 0$.

(2) If the importance of criteria $\mathrm{C}_{\mathrm{i}}$ is equal to that of $\mathrm{C}_{\mathrm{j}}$, $\mathrm{a}_{\mathrm{ij}}=\mathrm{a}_{\mathrm{ji}}=1$.

Therefore, matrix table A could be written as shown in Figure 2. Then, the respondents processed the paired comparison, as shown in Equation 1. where

$\mathrm{N}=$ The number of the comparison.

$\mathrm{n}=$ The number of the factors to be used in the paired comparison.

$$
\mathrm{N}=\frac{\mathrm{n}^{2}-\mathrm{n}}{2}
$$

The AHP was used to calculate the appropriate value to represent the weight for the paired comparison (Saaty, 2008). When comparing the criteria in the matrix table, in the vertical and horizontal lines, the eigenvector of the matrix was calculated in each line.

$$
\mathrm{A}_{\mathrm{w}}=\lambda_{\text {max }} \mathrm{w}
$$

where

A is the square matrix of the level of the respondents' opinion that is represented with the number at 1 (normalized).

$\mathrm{w}$ is the eigenvector representing the significance of the weight that is in the same level or group under the higher hierarchy.

$\lambda_{\text {max }}$ is the maximum eigenvalue from the total value of each criterion of each line multiplied with the horizontal average value of each line. Then, calculate the consistency index (C.I.):

$$
\text { C.I. }=\frac{\left(\lambda_{\max }-n\right)}{(n-1)}
$$

and find the random consistency index (R.I.) where the $\mathrm{RI}$ is varied to the size of the matrix process the consistency ratio $(\mathrm{CR})$. The $\mathrm{CR}$ should not be over $10 \%$ to indicate the consistency of the data, as shown in Equation 4.

$$
\mathrm{CR}=\frac{\text { C.I. }}{\text { R.I. }}
$$

\section{Methodology}

The prioritization of the significance of the factors in order to choose the Incoterms of the case study's selected automotive parts assembly company was the factor to be considered before making the agreement on the imports or exports. Therefore, this research compiled the secondary data from the study on the import and export protocol of the case study company and monitored the obstacles during the process, as well as collected the factors from the relevant research (Huuhka, 2019; Sabariah \& Szu, 2017; Shangina, 2007; Szu, 2014; Yaakub et al., 2018) to analyze the factors affecting the decision on the Incoterms.

This research was divided into five steps (Figure 1) commencing with the identification of the research objectives. Steps 2 reviewed the relevant literature, collected the data, and conducted an in-depth interview with the concerned persons with the decision-making on the Incoterms to determine the main and sub-criteria. Steps 3 set a preliminary questionnaire for the respondents to verify the main and sub-criteria and determine the alternatives for the company. Step 4 implemented the decisionmaking process with various factors by asking the person responsible for the decision-making to complete the AHP online application. The researcher surveyed the opinion of three authorized persons who had import and export experience by completing the questionnaire. Step 5 was to analyze, discuss and summarize the data. The research framework aimed to study the factors of the Incoterms by analyzing with the AHP from Level 1 - identification of the objective or problem of the study, Level 2 - identification of the main factors, Level 3 - identification of the secondary factors, and Level 4 - identification of the alternatives of the trade agreement (Figure 2).

This research considered that the main criteria involved four aspects: operating costs, cooperation and bargaining power, operation duration, and knowledge and understanding. From all the main criteria, there were 15 sub-criteria for considering the alternatives to the Incoterms. This research determined the consideration of the alternatives from four agreements of the most commonly used incoterms: Ex Works (EXW), Free Carrier (FCA), Free on Board (FOB), and Cost, Insurance and Freight (CIF). 


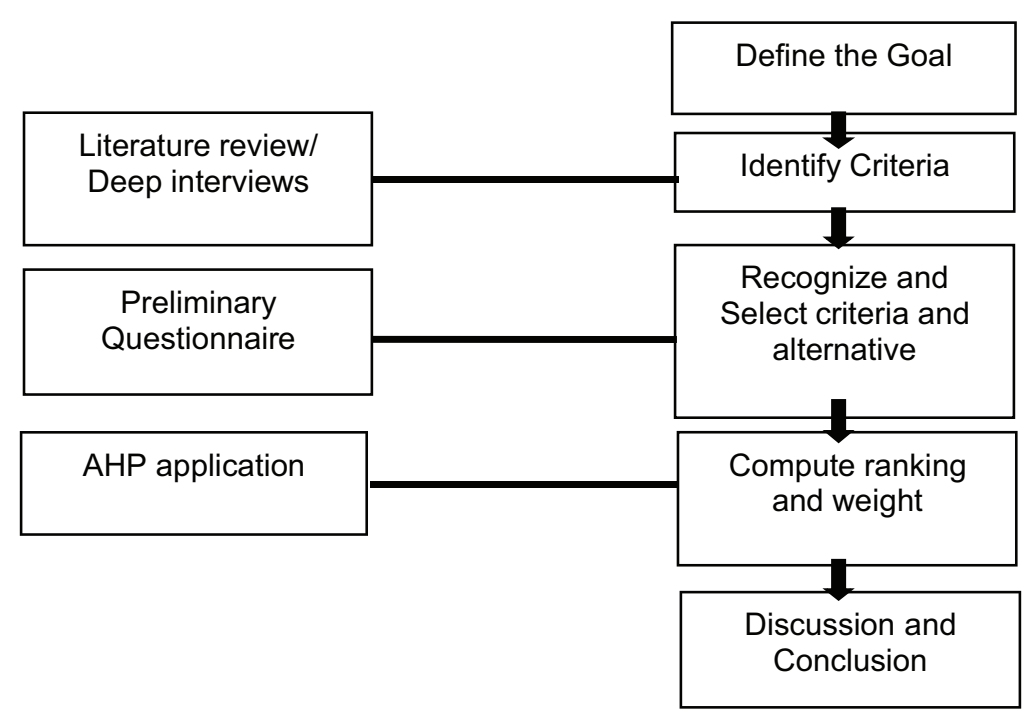

Figure 1: AHP based decision conceptual framework

Goal

Main criteria

Sub-criteria

Alternatives

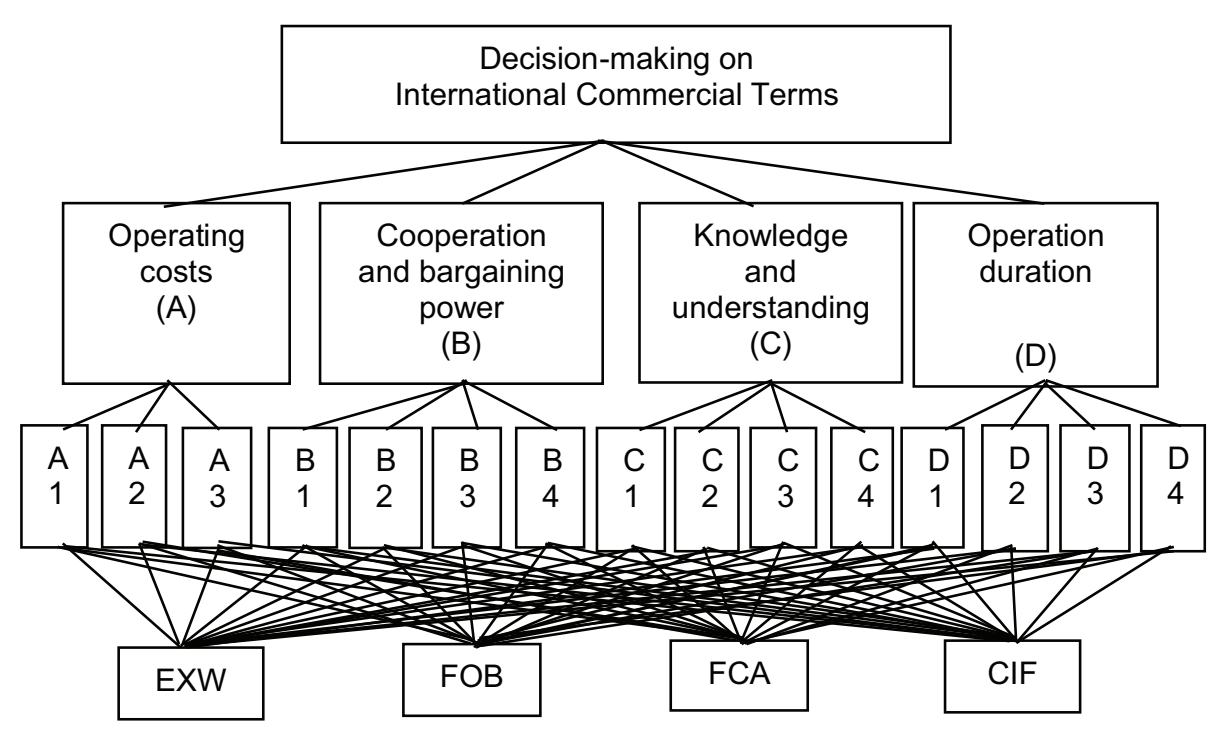

Figure 2: Hierarchical structure of decision-making on Incoterms

\section{Results and Discussion}

The analysis results with the AHP showed the weight of significance by being classified into three parts.

Part 1. The main criteria in Table 1 showed that the inconsistency was 0.005 , and the AHP consensus was at a high level (88.9\%), which implied that the respondents agreed on the score of the main criteria. Regarding the
AHP analysis, Table 1 showed that the significant weight and ranking of the main criteria for the decision-making on the Incoterms was the operating costs $\left(1^{\text {st }}\right)$, followed by knowledge and understanding $\left(2^{\text {nd }}\right)$, cooperation and bargaining power $\left(3^{\text {rd }}\right)$, and operation duration $\left(4^{\text {th }}\right)$, respectively.

Part 2. The analysis of the results of the sub-criteria affecting the decision-making on the Incoterms for the import and export is shown in Table 2. 
Table 1: The priority weights and ranking of main criteria

\begin{tabular}{|c|c|c|c|c|c|c|}
\hline \multirow{2}{*}{$\begin{array}{l}\text { Main } \\
\text { criteria }\end{array}$} & \multicolumn{4}{|c|}{ Criteria pairwise } & \multirow{2}{*}{$\begin{array}{c}\text { Relative } \\
\text { weight }\end{array}$} & \multirow{2}{*}{$\begin{array}{l}\text { Relative } \\
\text { ranking }\end{array}$} \\
\hline & A & B & C & D & & \\
\hline$A$ & 1 & 7.9581 & 7.559 & 5.5178 & 0.6966 & $1^{\text {st }}$ \\
\hline$B$ & 0.1256 & 1 & 1 & 1 & 0.0974 & $3^{\text {rd }}$ \\
\hline C & 0.1322 & 1 & 1 & 0.7631 & 0.0918 & $4^{\text {th }}$ \\
\hline$D$ & 0.1812 & 1 & 1.3103 & 1 & 0.1141 & $2^{\text {nd }}$ \\
\hline
\end{tabular}

Table 2: The priority weights and ranking of sub-criteria

\begin{tabular}{|c|c|c|c|c|c|}
\hline Main criteria & Sub-criteria & $\begin{array}{l}\text { Relative } \\
\text { Weight }\end{array}$ & $\begin{array}{l}\text { Relative } \\
\text { Ranking }\end{array}$ & $\begin{array}{l}\text { Global } \\
\text { Weight }\end{array}$ & $\begin{array}{c}\text { Global } \\
\text { Ranking }\end{array}$ \\
\hline \multirow{3}{*}{$\begin{array}{l}\text { A. Operating } \\
\text { costs }\end{array}$} & A1. Expenses of each shipment & 0.3028 & 2 & 0.2109 & $2^{\text {nd }}$ \\
\hline & A2. Annual budget & 0.4992 & 1 & 0.3478 & $1^{\text {st }}$ \\
\hline & A3. Value of products & 0.1978 & 3 & 0.1378 & $3^{\text {rd }}$ \\
\hline \multirow{4}{*}{$\begin{array}{l}\text { B. Cooperation } \\
\text { and } \\
\text { bargaining } \\
\text { power }\end{array}$} & B1. Negotiation between the buyer and seller & 0.1662 & 3 & 0.0161 & $12^{\text {nd }}$ \\
\hline & B2. Trust between the seller and buyer & 0.1717 & 2 & 0.0167 & $11^{\text {st }}$ \\
\hline & B3. Collaboration within the company & 0.0754 & 4 & 0.0073 & $14^{\text {th }}$ \\
\hline & B4. Agreed terms between the seller and buyer & 0.5868 & 1 & 0.0571 & $4^{\text {th }}$ \\
\hline \multirow{4}{*}{$\begin{array}{l}\text { C. Operation } \\
\text { duration }\end{array}$} & C1. Payment terms & 0.4539 & 1 & 0.0416 & $6^{\text {th }}$ \\
\hline & C2. Transportation period & 0.3329 & 2 & 0.0305 & $7^{\text {th }}$ \\
\hline & C3. Duration to change carriers & 0.1360 & 3 & 0.0124 & $13^{\text {rd }}$ \\
\hline & C4. Duration for risk taking & 0.0770 & 4 & 0.0070 & $15^{\text {th }}$ \\
\hline \multirow{4}{*}{$\begin{array}{l}\text { D. Knowledge } \\
\text { and } \\
\text { understanding }\end{array}$} & D1. Incoterms Rules & 0.2216 & 2 & 0.0253 & $8^{\text {th }}$ \\
\hline & D2. Experience in choosing Incoterms & 0.1971 & 3 & 0.0225 & $9^{\text {th }}$ \\
\hline & D3. International trade laws & 0.3854 & 1 & 0.0439 & $5^{\text {th }}$ \\
\hline & D4. Complicated documents & 0.1957 & 4 & 0.0223 & $10^{\text {th }}$ \\
\hline
\end{tabular}

From the analysis of the results of the main criteria, it was concluded that the operating costs $(0.6966)$ were the most important factor affecting the decision-making on choosing the Incoterms. This was because the company estimated the operating costs every year to plan the annual budget. Thus, the decision on the Incoterms for each shipment should firstly be considered from the set budget, followed by the expenses of each shipment, and the value of the products of each shipment.

Knowledge and understanding about international trade $(0.1141)$ was ranked second. An understanding of the international trade laws of the partner country would be crucial for choosing the Incoterms. Then, an understanding in each Incoterm rules, which had different conditions of responsibility, would also be important. Experience in choosing the Incoterms with the partner and an understanding in the complicated documents were significant as well.

After considering the costs of the company and the laws of the partner company, the company chose the Incoterms from the cooperation and bargaining power (0.0974). The sub-criteria involved the agreed terms between the seller and buyer, the trust between the seller and buyer, the negotiation between the buyer and seller, and the collaboration within the company.

The operation duration (0.0918) was the last criteria for consideration, which should be acknowledged from the sub-criteria involving the payment terms, the transport period as shown in the Incoterms, duration to change the carriers, and duration for risk taking as set in the Incoterms, respectively. 
In addition, the analysis of the result of the global ranking of 15 sub-criteria showed that the company considered the Incoterms from the budget (0.3478), expense of the transport per time (0.2109), and the value of the products per shipment (0.1378). It was obvious that the three sub-criteria were under the operating costs. The analysis of the results was consistent with the main criteria that the company prioritized as the top preference for choosing the Incoterms.

Part 3. The analysis of the results of the sub-criteria affecting the decision-making to choose the Incoterms for import and export is shown in Table 3.

Apart from the study on the main and sub-criteria, this research conducted an analysis to rank the appropriate Incoterms for the case study company as follows;

Firstly, the FCA(0.3558) was applicable to various transport methods. For the importer, the partner, as the exporter, should deliver the products at the designated location by the carrier's vehicle hired by the company. In using this alternative, the operation budget could be estimated. Therefore, the exporter processed the export customs clearance, which was more convenient than being processed by the company.

Secondly, the EWX (0.3280) where the buyer collected the products at the designated location without loading the products onto the vehicle. The company processed the import and export customs clearance.

Thirdly, the FOB (0.2010) that was one of the most popular Incoterms, especially for maritime transport. The exporter delivered the product by loading onto the importer's cargo ship at the port of origin identified in the agreement. The exporter processed the export customs clearance. However, this might have a cost for damage after loading onboard.

Lastly, the CIF (0.1059) that was limited to only maritime transport. The exporter must sign the insurance agreement and pay for the insurance, as well as all expenses until the delivery process is completed. The importer received the products when they were loading onboard at the designated port and received the products from the transporter at the designated destination port.

\section{Conclusion}

The selection of the Incoterms for the import and export of the automotive parts industry is the key factor for the company to consider since these would be the conditions that the buyer and seller would have the same understanding about the payment, transport, and liability (Kaweenuntawong, 2007). In general, to decide on the Incoterms, the significance of the criteria affecting the decision-making in the automotive parts manufacturing and assembly companies should consider to assess the alternatives as the guidelines for the appropriate decision.

The findings indicated that the operating costs were the first criteria which the company should consider for choosing the Incoterms and be consistent with the analysis of the result of the three sub-criteria that the company rated as the top three criteria, which were the budget, expenses of the transport, and value of the products per shipment. It was also obvious that the operating costs of the company had the highest significance for choosing the Incoterms.

Furthermore, another factor to be considered was the agreed terms and conditions that the seller and buyer had settled upon and the laws and regulations of the partner's country because this would have an impact on the contract, which was specific for each shipment. Moreover, the protocol was necessary to steer a smooth and efficient operation.

This research prioritized the selection of the Incoterms and found that the FCA was the first selected Incoterm. This findings concurred with the research of Schaefer (2017) who discovered that the value from the agreement was significant because it indicated the profit from the import and export, and the FCA was the selected Incoterm since the buyer handled all the expenses, except for the export customs clearance which the seller undertook in their own country. Therefore, the overview of the transport management was efficient.

In concluding, further research should include more respondents who are proficient in other related divisions to consider the criteria and factors because the import and export protocol requires the cooperation of divisions that have encountered various problems caused by different Incoterms. Thus, the overview of the significance of the criteria and factors affecting the decision-making on the Incoterms would be clearer. In addition, other alternatives of the Incoterms could be proposed depending on the specific situation of each company as the guidelines for the most appropriate decision.

Table 3: The priority weights and ranking of alternatives

\begin{tabular}{|l|c|c|}
\hline Alternatives & Relative weight & Alternative ranking \\
\hline EXW (Ex Works) & 0.3280 & 2 \\
\hline FOB (Free on Board) & 0.2101 & 3 \\
\hline FCA (Free Carrier) & 0.3558 & 1 \\
\hline CIF (Cost Insurance and Freight) & 0.1059 & 4 \\
\hline
\end{tabular}




\section{References}

Amrina, E., \& Yusof, S. M. (2013). An AHP based-model for sustainable manufacturing performance evaluation in automotive industry. Proceedings of the International Symposium on the Analytic Hierarchy Process, 1-9. https://doi. org/10.13033/isahp.y2013.016

An, H. J., \& Kim, W. K. (2019). A case study on the influence factors of financial performance of Korean automotive parts cooperation companies through research hypothesis. Journal of Asian Finance, Economics and Business, 6(3), 327-337. https://doi.org/10.13106/jafeb.2019.vol6.no3.327

Arvis, J. F., Duval, Y., Shepherd, B., Utoktham, C., \& Raj, A. (2016). Trade costs in the developing world: 1996-2010. World Trade Review, 15(3), 451-474. https://doi.org/10.1017/ S147474561500052X

Bergami, R. (2006). The link between Incoterms 2000 and Letter of Credit documentation requirement and payment risk. Journal of Business Systems Governance \& Ethics, 1(4), 51-60.

Bergami, R. (2012). Incoterms 2010: Comments on the new revision of delivery terms. Acta Universitatis Bohemiae Meridionales, 15(2), 33-40.

Chamsuk, W. (2018). Factor affecting to supply chain risk in Thai automotive industry. Business Review, 10(1), 123-142. Retrieved August 7, 2020 from https:/www.tci-thaijo.org/ index.php/bahcuojs/article/view/162260

De, P. (2007). Impact of trade costs on trade: Empirical evidence from Asian countries. Trade Facilitation beyond the Multilateral Trade Negotiations: Regional Practices, Customs Valuation and Other Emerging Issues - A Study by the AsiaPacific Research and Training Network on Trade, 27, 281-307.

Dweiri, F., Kumar, S., Khan, S. A., \& Jain, V. (2016). Designing an integrated AHP based decision support system for supplier selection in automotive industry. Expert Systems with Applications, 62, 273-283. https://doi.org/10.1016/j. eswa.2016.06.030

Galankashi, M. R., Helmi, S. A., \& Hashemzahi, P. (2016). Supplier selection in automobile industry A mixed balanced scorecardfuzzy AHP approach. Alexandria Engineering Journal, 55(1), 93-100.

Goepel, K. D. (2017). Implementation of an online software tool for the analytic hierarchy process. International Journal of the Analytic Hierarchy Process, 10(3). DOI: 10.13033/ijahp. v10i3.590

Hien, N., Laporte, G., \& Roy, J. (2014). Business environment factors, incoterms selection and export performance. Operations and Supply Chain Management: An International Journal, 2(2), 63-78. https://doi.org/10.31387/oscm040017

Huuhka, H. (2019). Effective use of Incoterms in the case company. Satakunta University of Applied Science, Finland.

Imarromna, J. (2011). Incoterms 2010 international trade conditions for international traders. FEU Academic Review, 4(2), 23-31.
International Chamber of Commerce. (2010). Incoterms ${ }^{\circledR}$ rules history. Retrieved August 7, 2020, from https://iccwbo.org/ resources-for-business/incoterms-rules/incoterms-ruleshistory/

Kaweenuntawong, J. (2007). Legal issue concerning the principle of transfer of risk transferee is the plaintiff in a lawsuit filed with the Thai court. Master thesis, Bangkok University, Thailand.

Khreusaeng, P. (2007). Legal status of Incoterms according to Thai law through a comparative study with foreign laws. Master thesis, Bangkok University, Thailand.

Konpong, N. (2019). Risk factors affecting to production planning in automotive parts industry. Burapha University, Thailand.

Limtrakul, S., \& Pimchanthong, D. (2019). Decision-making support system for car buying using analytical hierarchy process (AHP). Pathumthani University Academic Journal, 11(1), 104-111.

Lowe, D. (2020). Incoterms ${ }^{\circledR} 2020$ vs 2010: What's changed? Retrieved August 7, 2020 from https://icc.academy/incoterms2020-vs-2010-whats-changed/

Malfliet, J. (2011). Incoterms 2010 and the mode of transport: how to choose the right term. Management Challenges in the 21st Century: Transport and Logistics: Opportunity for Slovakia in the Era of Knowledge Economy, 163-179.

McKenzie, B. (2019). Procurement contracts and INCOTERMS; How to ensure your supply contracts are not incompatible with INCOTERMS. Retrieved August 7, 2020 from https://www. lexology.com/library/detail.aspx?g=4d25c17b-fc34-4b7a8154-21a6aa78aafb

Ngmsanengent, W. (2012). A comparative study of the logistic management in the automotive industry from manufacturers and third-party logistics providers' perspectives. Mater thesis, Rajamangala University of Technology Thanyaburi, Thailand.

Petruni, A., Giagloglou, E., Douglas, E., Geng, J., Leva, M. C., \& Demichela, M. (2017). Applying Analytic Hierarchy Process (AHP) to choose a human factors technique: Choosing the suitable Human Reliability Analysis technique for the automotive industry. Safety Science, 119, 229-239. https://doi. org/10.1016/j.ssci.2017.05.007

Rathi, R., Khanduja, D., \& Sharma, S. K. (2015). Synergy of fuzzy AHP and six sigma for capacity waste management in Indian automotive industry. Decision Science Letters, 4(3), 441-451. https://doi.org/10.5267/j.ds1.2015.1.005

Ronai, B. (2020). Incoterms 20207 Key Changes you need to know. Retrieved August 7, 2020 from: https://www. tradefinanceglobal.com/posts/incoterms-2020-7-key-changesyou-need-to-know/\#: :text=Incoterms 2010 rules assumed that seller in the D rules.

Saaty, T. L. (2008). Decision making with the analytic hierarchy process. International Journal of Services Sciences, 1(1), 83. https://doi.org/10.1504/IJSSCI.2008.017590

Sabariah, C., \& Szu, L. Y. (2017). Factors influencing the choice of Incoterms among Malaysian manufacturers. In: 6th International Conference on Social Sciences Research 2017, 
4th December 2017, Kuala Lumpur, Malaysia. http://repo.uum. edu.my/23069/

Sawangpaew, K. (2012). The study on the possibility in changing an agreement sale of goods between CIP (Incoterms 2000) and DDP (Incoterms 2010): A case study of advanced information technology public Co. Ltd. Journal of Politics, Administration and Law, 4(1), 287-340.

Schaefer, T. J. (2017). Incoterms ${ }^{\circledR}$ use in buyer-seller relationships: A mixed methods study. Dissertation, University of MissouriSt. Louis.

Shangina, O. A. (2007). Main factors in choice of delivery terms: a multiple case study of Japanese and Russian importers in seafood trade with Norway. Retrieved August 7, 2020 from https://doi.org/10.1080/00102208008946937

Shiphub. (2020). Incoterms 2020. Retrieved July 20, 2020 from https://www.shiphub.co/incoterms-2020/

Stapleton, D. M., Pande, V., \& Brien, D. O. (2013). EXW, FOB or FCA?: Choosing the right Incoterm and way it matters to maritime shippers. Journal of Transportation Law, Logistics \& Policy, 81(3), 227-248.
Szu, L. Y. (2014). Relationship between Incoterms choices, selection factors and export performance: a case of manufacturing companies in Malaysia. Retrieved August 7, 2020 from https:// doi.org/10.1530/EJE-14-0355

ThailandBoardofInvestment.(2017). Thailand'sautomotiveindustry: The next-generation. Retrieved August 7, 2020 from https:// www.boi.go.th/index.php?page=business_opportunities_detail \&topic_id=117517

Trang, T. Van, \& Do, Q. H. (2020). Critical success factors of TQM implementation in Vietnamese supporting industries. Journal of Asian Finance, Economics and Business, 7(7), 391-401. https://doi.org/10.13106/jafeb.2020.vol7.no7.391

Tu, M. T. C., \& Giang, H. T. T. (2018). Estimating the impact of trade cost on export: A case study Vietnam. Journal of Asian Finance, Economics and Business, 5(3), 43-50. https://doi. org/10.13106/jafeb.2018.vol5.no3.43

Yaakub, S., Szu, L. Y., Arbak, S., \& Halim, N. A. (2018). INCOTERMS selection factors and its effect on export performance. Journal of Advance Research in Business, Marketing, and Supply Chain Management, 2(1), 9-18. 